\title{
A new approach to over-bedding in American healthcare: Statistical analysis and computer simulation of patient admission in a West Virginia state psychiatric hospital
}

\author{
Wanhong Zheng*1, Minqi $\mathrm{Li}^{2}$, Michael Nickasch ${ }^{3}$, Feng Yang ${ }^{2}$, Aida Rabiee Gohar ${ }^{2}$ \\ ${ }^{1}$ Department of Behavioral Medicine and Psychiatry, West Virginia University School of Medicine, Morgantown, West Virginia, \\ United States \\ ${ }^{2}$ Department of Industrial and Management Systems Engineering, West Virginia University Benjamin M. Statler College of \\ Engineering and Mineral Resources, Morgantown, West Virginia, United States \\ ${ }^{3}$ West Virginia University School of Medicine, Morgantown, West Virginia, United States
}

Received: July 27, 2015

DOI: $10.5430 /$ jha.v5n $1 \mathrm{p} 18$
Accepted: October 4, 2015

Online Published: October 21, 2015

\begin{abstract}
Objective: To identify the factors that have a substantial impact on a West Virginia state psychiatric hospital's bed occupancy by investigating historical admission data, and developing a computer simulation system to give insight into modifiable variables that reduce admission numbers, therefore to provide solutions to the over-bedding problem.

Methods: Quantitative review of hospital admission data from January 2007 to November 2013 allowed for the construction of a simulation model to estimate the inpatient flow. The system's performance was evaluated after alteration of selected parameters and variables.

Results: The study revealed significant regional differences in admission numbers. The civil commitments and psychiatric hospitalizations do not directly correlate with county coverage populations. Some counties sent disproportionately more patients. Patients' length of stay also varied among geographical areas. Re-admission was not uncommon. Using the percentage of diversion as the outcome measurement, the computer simulation model reconstructed the admission scenario multiple times, predicting that the diversion rate can be significantly reduced if certain variables (hospital capacity, patient arrivals from top referring counties, and patient length of stay) are changed.

Conclusions: Involuntary admissions were unevenly distributed according to geography and population in the studied American state psychiatric hospital. Using historical data, computer simulations can model hospital admission systems to evaluate performance and predict needs for change.
\end{abstract}

Key Words: State hospital, Patient admission, Hospital capacity, Computer simulation, Optimization

*Correspondence: Wanhong Zheng; Email: wzheng@hsc.wvu.edu; Address: Department of Behavioral Medicine and Psychiatry, School of Medicine, West Virginia University, Morgantown, West Virginia 26505, United States. 


\section{INTRODUCTION}

\subsection{Background}

Every year, an enormous amount of money is spent on direct and indirect care for people suffering from various mental illnesses. In 2006, 36.2 million Americans paid for mental health services totaling $\$ 57.5$ billion, with an average expenditure of $\$ 1,591.00$ per person. ${ }^{[1]}$ Many patients received highly expensive inpatient care. ${ }^{[2,3]} 10 \%$ were treated at state and county mental hospitals. ${ }^{[4]}$ In $2009,163,276$ patients were treated in state psychiatric hospitals with corresponding expenditures of $\$ 9.8$ billion, with average personal daily cost reaching $\$ 570.00 .^{[5]}$ In 2011, the median length of stay for patients aged 18 and over was 58 days. ${ }^{[6]}$ Furthermore, from 2001 to 2009 , state funding declined by $1.2 \%$ per year. ${ }^{[5]}$ The subsequent over-bedding problem in many state hospitals has led to increasing concern about availability and adequacy of psychiatric care to severely mentally disturbed patients. ${ }^{[7]}$ Many researchers have concluded that over-bedding in hospital can have a considerable, negative impact on patient care ${ }^{\left[{ }^{8-10]}\right.}$ Maintaining the quantity and quality of psychiatric care for state hospital patients grows increasingly challenging with rising patient numbers and shrinking budgets. ${ }^{[1,12]}$ It is widely recognized that we must utilize the limited resource of hospital beds more efficiently. Unfortunately, we are often frustrated as a result of uncertainty regarding how to best address this complex issue. Identifying the critical areas for optimization of the admission process is the first imperative step toward system improvement.

Simulation is the imitation of a real-world process or system. ${ }^{[13]}$ It is a sampling experiment to answer questions about complex problems. ${ }^{[14]}$ Usually a model is built to represent the key characteristics or behaviors of the selected system or process in order to gain insight into their functioning. ${ }^{[13-15]}$ Its use in the field of psychiatry has been growing progressively in the past half century. In the late 1950s to early 1960s, simulations were already used to model neurotic processes, ${ }^{[16]}$ verbal learning behavior, ${ }^{[17]}$ social behavior, ${ }^{[18]}$ and even human thoughts. ${ }^{[19]}$ It was further recently clinically used in psychiatric consultation, ${ }^{[20]}$ psychological and psychiatric assessment, ${ }^{[21,22]}$ treatment and training. ${ }^{[23-26]}$ Unquestionably, computer simulation is progressively gaining presence in the mental health field, but there has been no focus on patterns of hospital admission and utilization to search for optimized solutions to overcrowding. Our study attempts to address this by building a computer simulation of hospital admission based on statistical analysis of the hospital's historical admission data.

\subsection{Problem statement and significance}

In the U.S., the responsibility of involuntary commitment for psychiatric evaluation and treatment falls to state and local

Published by Sciedu Press governments. ${ }^{[27]}$ The overall process is governed by state laws, regulations, polices, and budgeting choices. While there may be variances in the state and local bureaucratic systems of involuntary psychiatric commitment, the overall schema holds steadfast in its reliance on state-run psychiatric facilities as centers for treating this important patient population. It is without doubt that each state psychiatric hospital in the U.S. plays a major role in providing immediate inpatient care as intended by the laws; yet almost all are facing the same challenge to serve this population in crisis: patient over-bedding.

In West Virginia, there are two state-funded acute inpatient psychiatric hospitals with a total of 260 beds. Each hospital has a designated catchment area. Both hospitals only accept involuntary patients, either through civil commitments or court order. For civil commitment, the initial commitment (IC) is called Probable Cause and the patient can be involuntarily hospitalized for up to 30 days. If the patient continues to pose an imminent danger to self or others, he or she can be finally committed (FC) for further hospitalization.

The record from the studied state hospital and a previous study showed that since 2002 , it has been regularly above its designed capacity. ${ }^{[28]}$ Community hospital diversion is a temporary solution that has been extensively used at both state hospitals. This diversion approach carries several drawbacks: (1) it plays a limited role in improving the quality of patient care; (2) its implementation frequently encounters difficulties caused by bed availability, selection criteria, and location remoteness; and (3) it is highly expensive. In the long term, heavy reliance on community hospital diversion may prove costlier, and less frequently result in high-quality patient care.

To the best of our knowledge, no scientific research has been performed to systematically investigate the cause and solution to the over-bedding problem at state mental hospitals. With data from statistical analysis of historical admissions, a computer simulation system can replicate hospital daily admission, diversion, and patient length of stay, giving scientific insight into how different variables can be changed to reduce admission numbers. This can ideally be used for hospital administration and state-level mental health planning, especially policies regarding hospital expansion or patient diversion.

\section{MATERIALS AND METHODS}

\subsection{Study setting and subjects}

This study was conducted at William R. Sharpe Jr. Hospital, which is one of the two state psychiatric hospitals in West Virginia. The hospital has 150 beds and only admits court- 
ordered forensic patients or involuntary civilly committed patients. It serves 42 of West Virginia's 55 counties, and about $65 \%$ of the population. By the time of this study, there were about 75 forensic patients and 75 civil commitments so only half of the hospital beds were used for civilly committed patients. All patients were age 18 or older. For civil commitments, there are two types of legal status: initial and final. Both can be extended if patient continues to be an imminent danger to self or others. In this study we want to focus on civil commitment admission process. All court-ordered forensic patients were excluded.

\subsection{Data collection methods}

The William R. Sharpe Jr. Hospital admission office keeps an Excel spreadsheet that contains basic admission data, which includes medical record number, name, age, gender, county (where the patient was committed from), legal status, admission date, and discharge date. A research assistant created a new Excel database and de-identified personal data by removing their name, age, gender, and hashing medical record numbers into new item numbers. These item numbers were used to match patients who had more than one admission. The data was stored on a password-protected laptop, which was designated for this research study only. The West Virginia University institutional review boards and William $\mathrm{R}$ Sharpe Jr. Hospital research committee approved this study and granted a waiver regarding the need to obtain informed consent and Health Insurance Portability and Accountability Act authorization.

\subsection{Data analysis and simulation}

The patients were divided into different categories based on their legal status and counties of commitment. All patient arrivals from $1 / 2 / 2007$ to $11 / 29 / 2013$ were included in data analysis and simulation. The patient's length of stay was calculated by using the discharge date minus the admission date. In order to most accurately calculate bed occupying days, patients who remained hospitalized or were missing a discharge date by the end of the seven-year study window were assumed discharged on December 31, 2013. A simulation model was implemented in Matlab to investigate the performance of admission process in the hospital. The following notations are used to represent the collected historical data:

$T$ : The time horizon considered in this study which equals to 2,524 days.

$n_{1}$ : The number of IC patient arrivals during the time horizon; and $n_{1}=11,054$.

$n_{2}$ : The number of FC patient arrivals during the time horizon; and $n_{2}=848$. $\left\{a_{t}=\left(a_{t, 1}, a_{t, 2}\right) ; t=1,2, \ldots, T\right\}:$ The patient arrivals during the time horizon where $a_{t, 1}$ and $a_{t, 2}$ represent the numbers of IC and FC patient arrivals respectively for the $\mathrm{t}^{\text {th }}$ day.

$\left\{p_{i} ; i=1,2, \ldots, n_{1}\right\}$ : The length of stay of the $\mathrm{i}^{t h}$ IC patient. $\left\{q_{i} ; i=1,2, \ldots, n_{2}\right\}$ : The length of stay of the $\mathrm{i}^{\text {th }}$ FC patient.

\section{Simulation model}

To accommodate the stochastic nature of the process (e.g., random patient arrivals and lengths of stay), a simulation model was developed to mimic the hospital admission and hospitalization process. The simulation model consists of two main algorithms, which are given below.

Algorithm 1 simulates the patient arrivals over the time horizon, which are denoted as the bivariate time series $\left\{\tilde{\boldsymbol{a}}_{\boldsymbol{t}}\right.$; $t=1,2, \ldots, T\}$. The vector $\tilde{\boldsymbol{a}}_{\boldsymbol{t}}=\left(\tilde{a}_{t, 1}, \tilde{a}_{t, 2}\right)$ has two components $\tilde{a}_{t, 1}$ and $\tilde{a}_{t, 2}$ representing the simulated numbers of IC and FC patient arrivals respectively for the $t^{t h}$ day. Algorithm 1 is adapted from the resampling algorithm developed by Schruben and Singham ${ }^{[29,30]}$ to generate the bivariate non-negative integer time series $\left\{\tilde{\boldsymbol{a}}_{\boldsymbol{t}}\right.$; $t=1,2, \ldots, T\}$. Algorithm 1 takes as input the real historical data $\left\{\tilde{\boldsymbol{a}}_{t} ; t=1,2, \ldots, T\right\}$. There are two userspecified parameters: the affinity parameter $\lambda$ to control the similarity of $\tilde{\boldsymbol{a}}_{\boldsymbol{t}}$ to $\boldsymbol{a}_{\boldsymbol{t}}$, and the noise parameter $\sigma$ to model the uncertainty involved in patient arrivals. In this work, $\lambda$ is set as 0.65 , and $\sigma=0.55$. Interested readers are referred to Schruben and Singham ${ }^{[29,30]}$ for the specifics regarding these two parameters. To ensure that the simulated arrival numbers are non-negative integers, the outputs $\left\{\tilde{\boldsymbol{a}}_{\boldsymbol{t}} ; t=1,2, \ldots, T\right\}$ of Algorithm 2 are all rounded to the nearest non-negative integers. Multiple realizations of $\left\{\tilde{\boldsymbol{a}}_{\boldsymbol{t}}\right.$; $t=1,2, \ldots, T\}$ can be generated by Algorithm 1, and each realization represents a possible scenario of patient arrivals over the time horizon. Denote $I_{2}$ as the $2 \times 2$ identity matrix and $0_{2}$ as the zero vector of dimension 2. Algorithm 1 is detailed on next page.

Schruben and Singham's algorithm is chosen because it allows for resampling of real multivariate time series, without requiring the various restrictive assumptions as conventional methods do. Figure 1 plots over a 60-day period the historical patient arrivals and an example of the simulated arrivals from Algorithm 1. The simulation outputs resemble and deviate from the real data.

Algorithm 2 is developed to simulate the arrival, stay (or diversion), and departure of patients. The algorithm is detailed below. In Step 1, Algorithm 1 is called to generate the arrivals of the two types of patients over the time horizon. In Step 2, for each patient admitted into the hospital, the length of stay is simulated by the bootstrapping resampling 
method $^{[31]}$ based on the historical data for patients' length mined; during any day, FC patients have higher admission of stay, and subsequently a patient's departure time is deter- priority than IC patients if there are not sufficient beds.

Algorithm 1 The resampling algorithm for the simulation of patient arrivals

Inputs: (a) historical data $\left\{\boldsymbol{a}_{t} ; t=1,2, \ldots, T\right\}$; (b) affinity parameter $\lambda$; (c) noise parameter $\sigma$.

Initialization: randomly sample $\widetilde{\boldsymbol{a}}_{1}$ from the multivariate normal distribution $N\left(\boldsymbol{a}_{1}, \sigma^{2} \boldsymbol{I}_{2}\right)$.

Process:

FOR $t=2$ to $T$

Set $R_{t}$ as the Euclidean distance between $\widetilde{\boldsymbol{a}}_{t-1}$ and $\boldsymbol{a}_{t}$.

Randomly sample $\boldsymbol{\varphi}_{t}$ from $N\left(\mathbf{0}_{2}, \boldsymbol{I}_{2}\right)$ and $\boldsymbol{\varepsilon}_{t}$ from $N\left(\mathbf{0}_{2}, \sigma^{2} \boldsymbol{I}_{2}\right)$. Then

$$
\widetilde{\boldsymbol{a}}_{t}=\widetilde{\boldsymbol{a}}_{t-1}+\lambda\left(\boldsymbol{a}_{t}-\widetilde{\boldsymbol{a}}_{t-1}\right)+(1-\lambda) R_{t} \boldsymbol{\varphi}_{t}+\boldsymbol{\varepsilon}_{t} .
$$

\section{END FOR}

Outputs: $\left\{\widetilde{\boldsymbol{a}}_{t} ; t=1,2, \ldots, T\right\}$.

A simulation run is initiated with no patients in the hospital. The simulation length $T$ in Algorithm 2 is set as 2,524 days and the warm-up period $t_{0}$ is set as 365 days. Only the period $\left(t_{0}, T\right]$ is used to compute the diversion rate of patients, which is the output of Algorithm 2 and the performance metric of interest.

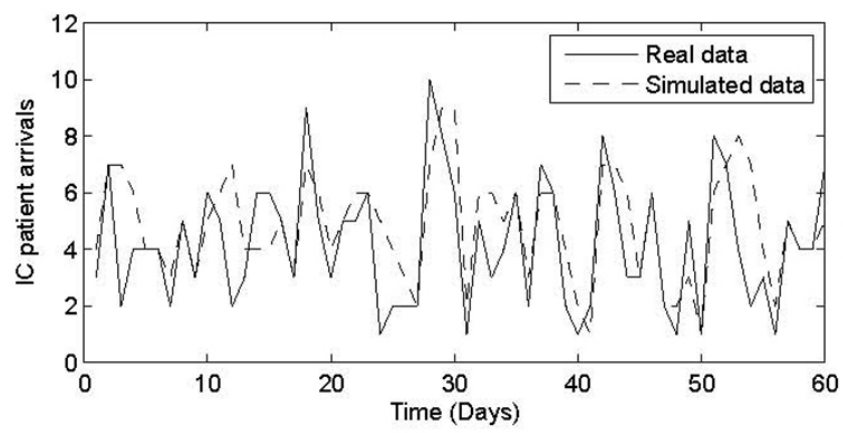

Figure 1. Simulated patient arrivals for 60 days

\section{Results}

\subsection{Statistical analysis}

Table 1 summarizes the civil commitment admission data of ten selected counties (top referring counties A-E; bottom referring counties F-J).

The total number of referring counties in the catchment area was 42. From 2007 through 2013, the number of total visits is 3,935 and total bed occupying days are 214,312 . The five counties with the greatest utilization of the state psychiatric hospital were A, B, C, D, and E respectively. These top five counties individually contributed the greatest to the state psychiatric hospital's civil patient population in terms of both total admissions (range of $21.70 \%-4.45 \%$ of hospital total) and bed utilization (ranging from $13.18 \%-5.83 \%$ of hospital total). Comparatively, Counties F, G, H, I, and J Published by Sciedu Press
Based on the hospital records from 01/02/2007 to 11/29/2013, there were a total of 11,902 incoming patients, among which 7,967 (66.94\%) patients were diverted. The actual diversion rate is compared to that estimated from the simulation experiments, to validate the simulation model in Section 3.2.

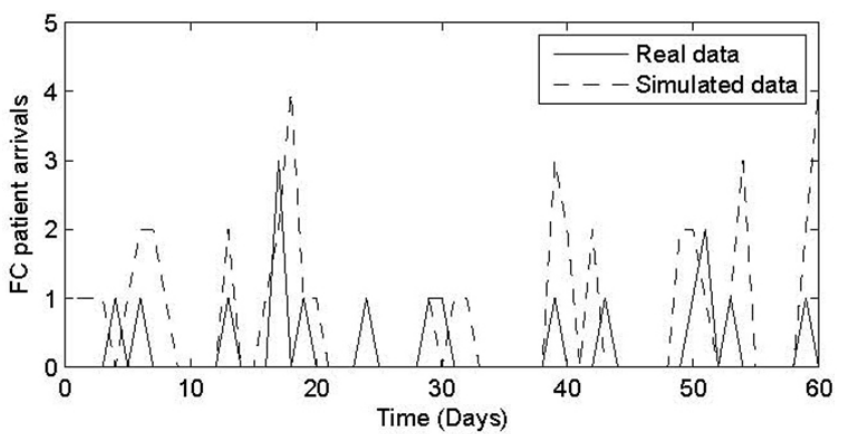

utilized the state psychiatric hospital the least, with ranges comprising $0.28 \%-0.64 \%$ of the hospital's total admissions and $0.11 \%-0.80 \%$ of the total bed occupancy. From Table 1, we can see that County A committed total of 2,294 $(854+1,440)$ patients. Of these, 1,440 patients had to be diverted to outside hospitals for treatment due to bed unavailability, admitting only 854 patients. These 854 patients from County A utilized a total of 28,240 bed-occupying days, equating to $21.70 \%$ of the total hospital admissions and $13.18 \%$ of the whole hospital bed occupation over the study duration. Table 1 shows that civil commitment admissions were disproportionately distributed among different counties. While there seems to be a stark contrast between the top and bottom referring counties, we must take into account population data to further address this discrepancy. 


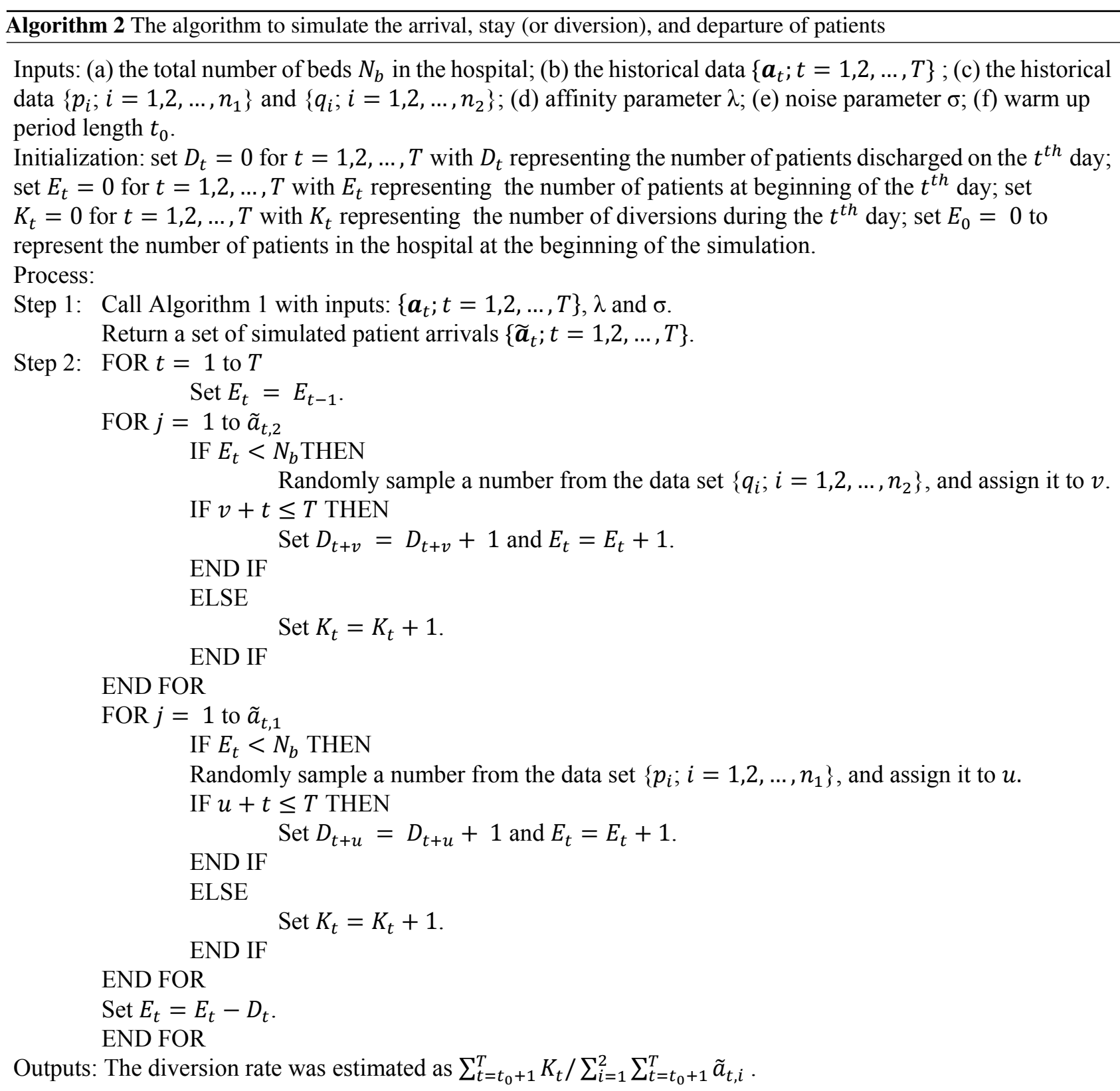

Utilizing the state and county quick facts from the United States Census Bureau from 2010-2013, ${ }^{[32]}$ Table 2 compares yearly population data and annual admission totals between counties selected in Table 1. While attempting to standardize the county admission data to control for sampling size bias, we can see that the number of admissions between counties is not proportional to population size. Ratios of civil commitment admissions per populace varied notably from $0.00 \%$ to $0.17 \%$, with County A having the highest ratio in years 2010 and 2011. Trending these ratios indicates a general decline in yearly admissions across the majority of the selected counties between the years 2010-2013, although County A remained the greatest contributor of admissions per populace throughout all four years examined.

Table 3 examines the patient (re)admission frequencies and respective bed occupying days of the entire study population admitted to the hospital over seven years (excluding diversion data; $\mathrm{n}=3,935$ admissions). It shows that the majority of patients had only one admission to the hospital, comprising $39.35 \%$ of the total bed occupancy. Readmission (>1 admission) was not uncommon; 12 patients had 10 or more admissions (one patient had 49 admissions). Readmitted patients significantly contributed to total bed occupancy; patients admitted more than once $(n=594)$ collectively utilized more than half $(60.65 \%)$ of the hospital's total bed occupancy; furthermore, 255 patients who were readmit- 
ted more than once ( $>2$ admissions) comprised $37.35 \%$ of lengthier hospitalizations per visit (excluding the 4 patients the total bed occupancy. Patients with one admission were with $>18$ admissions). The four patients with extremely high hospitalized an average of 41.01 total days; comparatively, readmissions ( $>18$ admissions) had shorter average visit readmitted patients utilized a greater percent of the hospital's durations.

total bed occupancy. On average, readmitted patients had

Table 1. Seven-year aggregate admission data of highest and lowest referring counties

\begin{tabular}{|c|c|c|c|c|c|c|c|c|c|c|}
\hline County & $\begin{array}{l}\text { Admissions } \\
(\text { IC + FC) }\end{array}$ & $\begin{array}{l}\text { Admission } \\
\text { Percentage } \\
\text { (of total) }\end{array}$ & $\begin{array}{l}\text { Bed } \\
\text { Occupancy } \\
\text { (days) }\end{array}$ & $\begin{array}{l}\text { Occupancy } \\
\text { Percentage } \\
\text { (of total) }\end{array}$ & $\begin{array}{l}\text { IC } \\
\text { Admissions }\end{array}$ & $\begin{array}{l}\text { IC Bed } \\
\text { Occupancy } \\
\text { (days) }\end{array}$ & $\begin{array}{l}\text { FC } \\
\text { Admissions }\end{array}$ & $\begin{array}{l}\text { FC Bed } \\
\text { Occupancy } \\
\text { (days) }\end{array}$ & $\begin{array}{l}\text { Total } \\
\text { Diversions }\end{array}$ & $\begin{array}{l}\text { Diversion } \\
\text { Percentage }\end{array}$ \\
\hline A & 854 & $21.70 \%$ & 28,240 & $13.18 \%$ & 793 & 23,321 & 61 & 4,919 & 1,440 & $62.77 \%$ \\
\hline B & 405 & $10.29 \%$ & 22,981 & $10.72 \%$ & 341 & 16,254 & 64 & 6,727 & 212 & $34.36 \%$ \\
\hline C & 289 & $7.34 \%$ & 16,886 & $7.88 \%$ & 213 & 6,646 & 76 & 10,240 & 572 & $66.43 \%$ \\
\hline D & 218 & $5.54 \%$ & 14,422 & $6.73 \%$ & 189 & 11,304 & 29 & 3,118 & 827 & $79.14 \%$ \\
\hline E & 175 & $4.45 \%$ & 12,495 & $5.83 \%$ & 133 & 8,218 & 42 & 4,277 & 723 & $80.51 \%$ \\
\hline $\mathrm{F}$ & 25 & $0.64 \%$ & 1,709 & $0.80 \%$ & 22 & 1,373 & 3 & 336 & 15 & $37.50 \%$ \\
\hline G & 18 & $0.46 \%$ & 1,482 & $0.69 \%$ & 14 & 877 & 4 & 605 & 10 & $35.71 \%$ \\
\hline $\mathrm{H}$ & 16 & $0.41 \%$ & 865 & $0.40 \%$ & 16 & 865 & 0 & 0 & 7 & $30.43 \%$ \\
\hline I & 15 & $0.38 \%$ & 241 & $0.11 \%$ & 14 & 228 & 1 & 13 & 15 & $50.00 \%$ \\
\hline $\mathrm{J}$ & 11 & $0.28 \%$ & 1,504 & $0.70 \%$ & 11 & 1,504 & 0 & 0 & 9 & $45.00 \%$ \\
\hline
\end{tabular}

Table 2. Annual admission totals and population data of ten selected counties 2010-2013

\begin{tabular}{|c|c|c|c|c|c|c|c|c|c|c|c|c|}
\hline County & 2010 & $\begin{array}{l}\text { Visits } \\
\text { in } 2010\end{array}$ & $\begin{array}{l}2010 \\
\text { Visits per } \\
\text { Populace }\end{array}$ & 2011 & $\begin{array}{l}\text { Visits } \\
\text { in } 2011\end{array}$ & $\begin{array}{l}2011 \\
\text { Visits per } \\
\text { Populace }\end{array}$ & 2012 & $\begin{array}{l}\text { Visits } \\
\text { in } 2012\end{array}$ & $\begin{array}{l}2012 \\
\text { Visits per } \\
\text { Populace }\end{array}$ & 2013 & $\begin{array}{l}\text { Visits } \\
\text { in } 2013\end{array}$ & $\begin{array}{l}2013 \\
\text { Visits per } \\
\text { Populace }\end{array}$ \\
\hline A & 86,982 & 152 & $0.17 \%$ & 86,844 & 126 & $0.15 \%$ & 86,657 & 69 & $0.08 \%$ & 86,569 & 73 & $0.08 \%$ \\
\hline B & 69,240 & 75 & $0.11 \%$ & 69,316 & 66 & $0.10 \%$ & 69,166 & 49 & $0.07 \%$ & 68,972 & 27 & $0.04 \%$ \\
\hline C & 56,524 & 34 & $0.06 \%$ & 56,661 & 40 & $0.07 \%$ & 56,849 & 26 & $0.05 \%$ & 56,868 & 20 & $0.04 \%$ \\
\hline D & 96,776 & 37 & $0.04 \%$ & 98,671 & 30 & $0.03 \%$ & 100,527 & 20 & $0.02 \%$ & 102,274 & 19 & $0.02 \%$ \\
\hline E & 78,913 & 20 & $0.03 \%$ & 79,259 & 23 & $0.03 \%$ & 79,177 & 22 & $0.03 \%$ & 78,833 & 15 & $0.02 \%$ \\
\hline F & 10,449 & 8 & $0.08 \%$ & 10,349 & 1 & $0.01 \%$ & 10,269 & 1 & $0.01 \%$ & 10,077 & 1 & $0.01 \%$ \\
\hline G & 8,693 & 5 & $0.06 \%$ & 8,765 & 1 & $0.01 \%$ & 8,778 & 1 & $0.01 \%$ & 8,650 & 0 & $0.00 \%$ \\
\hline $\mathrm{H}$ & 5,736 & 1 & $0.02 \%$ & 5,803 & 0 & $0.00 \%$ & 5,839 & 1 & $0.02 \%$ & 5,901 & 4 & $0.07 \%$ \\
\hline I & 9,154 & 1 & $0.01 \%$ & 9,148 & 1 & $0.01 \%$ & 9,016 & 1 & $0.01 \%$ & 8,881 & 0 & $0.00 \%$ \\
\hline $\mathrm{J}$ & 7,574 & 1 & $0.01 \%$ & 7,608 & 0 & $0.00 \%$ & 7,581 & 2 & $0.03 \%$ & 7,577 & 0 & $0.00 \%$ \\
\hline
\end{tabular}

Table 4 illustrates the length of hospitalization of all incoming civilly committed patients (including diverted patients at outside facilities) who were discharged with a valid discharge date (excluding 172 patients missing discharge data). When encompassing the diversion data, there were $11,730 \mathrm{com}$ mitments. Of these, 10,936 were IC patients and 794 were FC patients. The majority of IC patients $(9,862,90.18 \%$ of IC patients) were discharged within 30 days, which is the maximum legal time for involuntary hospitalization for this commitment status. Less than $10 \%$ of IC patients were recommitted to FC status, and were hospitalized longer. The longest patient stay was 1,661 days.

Some patients were admitted with the standing legal status of FC. These patients were committed for initial psychiatric treatment greater than 30 days, were discharged based on positive response to inpatient treatment, and were subsequently readmitted before completion of their final commitment. The majority of these patients stayed between 7 and 182.5 days $(664,83.63 \%)$, with a maximum length of stay of 2,131 days. Patients with zero bed occupying days were discharged within 24 hours of admission.

\subsection{Simulation results}

The simulation model developed is used to investigate the impacts on the system performance (i.e., the diversion rate of patients) of changing the hospital capacity (the total number of beds), patient arrivals, and their length of stay. These variables are required inputs (a)-(c) to Algorithm 2, the simulation algorithm. 
Table 3. Seven-year readmission frequencies and bed occupancy data

\begin{tabular}{llllll}
\hline $\begin{array}{l}\text { Number of Times } \\
\text { Admitted }\end{array}$ & $\begin{array}{l}\text { Number of } \\
\text { Patients }\end{array}$ & $\begin{array}{l}\text { Bed Occupancy } \\
\text { (days) }\end{array}$ & $\begin{array}{l}\text { Occupancy Percentage } \\
\text { (of total) }\end{array}$ & $\begin{array}{l}\text { Average Bed Occupying } \\
\text { Days per Patient }\end{array}$ & $\begin{array}{l}\text { Average Bed Occupying } \\
\text { Days per Visit }\end{array}$ \\
\hline 1 & 2,056 & 84,326 & $39.35 \%$ & 41.01 & 41.01 \\
2 & 339 & 49,941 & $23.30 \%$ & 147.32 & 73.66 \\
3 & 132 & 26,544 & $12.39 \%$ & 201.09 & 67.03 \\
4 & 54 & 12,565 & $5.86 \%$ & 232.69 & 58.17 \\
5 & 21 & 9,635 & $4.50 \%$ & 458.81 & 91.76 \\
6 & 16 & 13,121 & $6.12 \%$ & 820.06 & 136.68 \\
7 & 8 & 4,295 & $2.00 \%$ & 536.88 & 76.70 \\
8 & 8 & 3,389 & $1.58 \%$ & 423.63 & 52.95 \\
9 & 4 & 1,564 & $0.73 \%$ & 391.00 & 43.44 \\
11 & 1 & 688 & $0.32 \%$ & 688.00 & 62.55 \\
12 & 2 & 1,456 & $0.68 \%$ & 728.00 & 60.67 \\
14 & 1 & 625 & $0.29 \%$ & 625.00 & 44.64 \\
15 & 1 & 699 & $0.33 \%$ & 699.00 & 46.60 \\
17 & 3 & 3,000 & $1.40 \%$ & $1,000.00$ & 58.82 \\
19 & 1 & 725 & $0.34 \%$ & 725.00 & 38.16 \\
21 & 1 & 445 & $0.21 \%$ & 445.00 & 21.19 \\
49 & 1 & 467 & $0.22 \%$ & 467.00 & 16.68 \\
\hline 10 & 827 & $0.39 \%$ & 827.00 & 16.88 \\
\hline
\end{tabular}

${ }^{*}$ Total hospital bed occupying days: 214,312

Table 4. Summary of IC and FC bed occupancy for all arrivals and diversions

\begin{tabular}{lll}
\hline Length of Stay & $\begin{array}{l}\text { Number of IC } \\
\text { Patients }\end{array}$ & $\begin{array}{l}\text { Number of FC } \\
\text { Patients }\end{array}$ \\
\hline$\leq 7$ days & 4,128 & 78 \\
$>7$ days but $\leq 30$ days & 5,734 & 319 \\
$>$ 30 days but $\leq 182.5$ days & 994 & 345 \\
$>182.5$ days but $\leq 365$ days & 55 & 28 \\
$>$ 365 days & 25 & 24 \\
Range of Bed Occupying Days & & \\
Minimum & 0 & 0 \\
Maximum & 1,661 & 2,131 \\
\hline
\end{tabular}

Note. IC: Initial Commitment; FC: Final Commitment

Table 5. Estimated diversion change with adjusted hospital capacity

\begin{tabular}{lllll}
\hline $\begin{array}{l}\text { Beds } \\
\text { Available }\end{array}$ & Mean & $\begin{array}{l}\text { Standard } \\
\text { deviation }\end{array}$ & Reduction & CI of reduction \\
\hline $\mathrm{N}_{\mathrm{b}}=85$ & $61.26 \%$ & $2.38 \%$ & $5.70 \%$ & {$[5.41 \%, 5.99 \%]$} \\
$\mathrm{N}_{\mathrm{b}}=95$ & $55.29 \%$ & $2.72 \%$ & $11.67 \%$ & {$[11.36 \%, 11.98 \%]$} \\
$\mathrm{N}_{\mathrm{b}}=115$ & $42.85 \%$ & $3.31 \%$ & $24.11 \%$ & {$[23.76 \%, 24.46 \%]$} \\
\hline
\end{tabular}

Note. CI: Confidence Interval

The benchmark scenario sets these inputs as: (a) $N_{b}=75$; (b) the historical arrivals $\left\{a_{t} ; t=1,2, \ldots, T\right\}$; and (c) the historical length of stay for patients $\left\{p_{i} ; i=1,2, \ldots, n_{1}\right\}$ and $\left\{q_{i} ; i=1,2, \ldots, n_{2}\right\}$. For the benchmark scenario, 500 simulation replications were performed by executing Algorithm 2 for 500 times, leading to 500 diversion rate estimates.
Based on these estimates, the cross-replication average of the diversion rates is $66.96 \%$, the sample standard deviation is $2.23 \%$, and the $95 \%$ confidence interval (CI) was [66.76\%; $67.16 \%$ ], which includes the real historical diversion rate of $66.94 \%$. As given earlier, for the benchmark scenario, 500 simulation replications lead to the following statistics for the patient diversion rate: the cross-replication average is $66.96 \%$, the standard deviation is estimated as $2.23 \%$, and the $95 \% \mathrm{CI}$ is $[66.76 \% ; 67.16 \%]$.

By varying each of the three inputs (a)-(c), alternative scenarios are generated and compared to the benchmark scenario in the reminder of this section. For each scenario, 500 simulation replications are generated, and the corresponding statistics for diversion rate are obtained and presented in a series of tables (see Tables 5-7). Each table includes the following columns for a certain scenario: "Mean" and "Standard deviation" provide the cross-replication mean and standard deviation of the diversion rates for that scenario; The "Reduction" column represents the estimated decrease in expected diversion rates from the alternative scenario to the benchmark, and the "Cl" column gives the $95 \%$ CI of the expected decrease. An alternative scenario is significantly different from the benchmark in terms of their diversion rates, if the lower bound of the $\mathrm{CI}$ is greater than zero.

\subsubsection{Adding more beds}

To assess the impacts of adding more beds, the input (a) is varied to obtain three scenarios, with the hospital capacity 
being $N_{b}=85,95$, and 115 respectively. Table 5 provides the results, and the CIs quantify the expected reduction in diversion rates for an increased number of beds.

\subsubsection{Reducing the number of patient arrivals}

Table 6 illustrates the impacts of reducing patient arrivals (adjustment of input [b] in Algorithm 2) on diversion rates. Herein, the top five referring counties are considered, which count for $48.02 \%(5,715$ out of 11,902$)$ of the total number of patients based on the historical data. Alternative scenarios are generated by decreasing the patient referrals by $10 \%$ for each of the five counties, and the comparison results with the benchmark scenario are given in Table 6.

\subsubsection{Reducing the length of stay}

Table 7 summarizes the effects on the diversion rates of reducing the length of stay (Input [c] to Algorithm 2) by $10 \%$ for IC patients, FC patients, and both types of patients, respectively. The diversion rate decrease was noticed to be significant if the length of stay could be reduced.

Table 6. Estimated diversion change with adjusted patient arrivals

\begin{tabular}{llllll}
\hline & Counties & Mean & Standard deviation & Reduction & CI of reduction \\
\hline & County A only & $66.21 \%$ & $2.29 \%$ & $0.75 \%$ & {$[0.47 \%, 1.03 \%]$} \\
& County B only & $66.51 \%$ & $2.22 \%$ & $0.45 \%$ & {$[0.17 \%, 0.73 \%]$} \\
\multirow{2}{*}{$\begin{array}{l}10 \% \text { less patient } \\
\text { arrivals }\end{array}$} & County C only & $66.83 \%$ & $2.21 \%$ & $0.13 \%$ & {$[-0.15 \%, 0.41 \%]$} \\
& County D only & $66.51 \%$ & $2.20 \%$ & $0.45 \%$ & {$[0.18 \%, 0.73 \%]$} \\
& County E only & $66.59 \%$ & $1.98 \%$ & $0.37 \%$ & {$[0.11 \%, 0.63 \%]$} \\
& All of the 5 counties & $64.68 \%$ & $2.27 \%$ & $2.28 \%$ & {$[2.00 \%, 2.56 \%]$} \\
\multirow{2}{*}{$\begin{array}{l}20 \% \text { less patient } \\
\text { arrivals }\end{array}$} & County A only & $65.38 \%$ & $2.29 \%$ & $1.58 \%$ & {$[1.30 \%, 1.86 \%]$} \\
& County B only & $66.39 \%$ & $2.21 \%$ & $0.57 \%$ & {$[0.30 \%, 0.85 \%]$} \\
& County C only & $66.23 \%$ & $2.08 \%$ & $0.73 \%$ & {$[0.46 \%, 1.00 \%]$} \\
& County D only & $66.12 \%$ & $2.32 \%$ & $0.84 \%$ & {$[0.56 \%, 1.12 \%]$} \\
& County E only & $66.37 \%$ & $2.17 \%$ & $0.59 \%$ & {$[0.32 \%, 0.86 \%]$} \\
& All of the 5 counties & $62.72 \%$ & $2.42 \%$ & $4.24 \%$ & {$[3.95 \%, 4.53 \%]$} \\
\hline
\end{tabular}

Note. CI: Confidence Interval

Table 7. Estimated diversion change with adjusted length of stay

\begin{tabular}{llllll}
\hline & Patient Status & Mean & Standard deviation & Reduction & CI of reduction \\
\hline \multirow{3}{*}{$10 \%$ less length of stay } & IC patients & $65.51 \%$ & $2.32 \%$ & $1.45 \%$ & {$[1.17 \%, 1.73 \%]$} \\
& FC patients & $64.45 \%$ & $2.35 \%$ & $2.51 \%$ & {$[2.23 \%, 2.79 \%]$} \\
& Both & $62.78 \%$ & $2.45 \%$ & $4.18 \%$ & {$[3.89 \%, 4.47 \%]$} \\
\multirow{2}{*}{$20 \%$ less length of stay } & IC patients & $63.51 \%$ & $1.45 \%$ & $3.45 \%$ & {$[3.16 \%, 3.74 \%]$} \\
& FC patients & $61.77 \%$ & $2.51 \%$ & $5.19 \%$ & {$[4.91 \%, 5.47 \%]$} \\
& Both & $57.38 \%$ & $4.18 \%$ & $9.58 \%$ & {$[9.28 \%, 9.88 \%]$} \\
\hline
\end{tabular}

Note. CI: Confidence Interval; IC: Initial Commitment; FC: Final Commitment

\section{Discussion}

The involuntary state psychiatric hospitalization process can best be described as complicated. A multitude of factors drive this system's efficiency, performance, and quality. While this study's immediate focus is directed at highlighting solutions for the current insufficiencies facing West Virginia's state psychiatric system, its ideal underlying aim is to depict an easily replicable and adaptable scientific problemsolution framework that can aid in better administrative decision making and policy planning by means of outcome and cost-benefit maximization across a multitude of healthcare sectors and scenarios.
This study offers hospital managers and policy makers some insight into several specific areas to target when addressing over-bedding problems. From a practical psychiatric standpoint, we can focus on counties with high commitment numbers for possible solutions such as increasing the number of crisis unit beds to help patients who only require brief crisis intervention and short hospital stay; working closely with local mental health facilities in developing individualized long term treatment plans for patients with multiple admissions with special emphasis on psychiatric protective factors including family and social support, treatment adherence, and relapse or recurrence prevention etc. With the goal of reducing lengthy hospital stay, adding group homes or assisted 
living programs could greatly aid in relieving disposition issues that many state hospitals face. This can provide patients with stable therapeutic living environments for mental health improvement, medication compliance, and intervention efficacy. In terms of addressing the chronic and severe psychiatric patients with frequent readmissions, expansion and implementation of programs that mirror the Assertive Community Treatment (ACT) model ${ }^{[33]}$ could greatly help support these patients in receiving consistent high quality care and follow-up in the post-hospitalization period. As for hospital expansion and budgeting, this study provides a scientific way to justify the number of new beds needed to relieve current over-bedding stress based on historical capacity and daily census.

While the simulation shows reducing length of hospital stay can help with diversion rate, it is important to acknowledge quality of care concerns in terms of shortening patient hospitalization time. Equally pertinent, we must recognize the beneficial scope and limitations of inpatient psychiatric treatment. Prolonged length of hospitalization does not equate to superior health outcomes, but can mostly and often happen when disposition is deterred because no less restrictive placement could be found. Therefore from treatment team's standpoint, high quality of inpatient care is still the key to successful discharge even if the aforementioned recommendations can be implemented.

The limitations of our study lie in two areas: data insufficiency and scope/complexity of the problematic focus. Working with a concrete set of historical data narrowed our statistical analysis to admission and diversion numbers. Some of the retrospective data was not suitable for use and was excluded from the simulation model, as in the case of patients that remained hospitalized by the end of the study period and length of stay was uncertain. Moreover, some of the data used in statistical analysis lacked practical applicability from a solution standpoint, and were not incorporated in the computer algorithm. Readmission statistics for example, while useful in understanding the patient population and admission totals, were not used as a direct variable in the simulated algorithm, as the nature of its causality alone is multifactorial (i.e. severity of mental illness, suboptimal treatment outcomes, noncompliance, insufficient social support structures, etc.).

Secondarily, the scope/complexity of this problematic focus is a comprehensive limitation. While being able to incorporate some of the core contributing factors in the over-bedding equation (capacity, admissions, length of hospitalization, geographical admission distribution), we still need to consider a multitude of other variables such as patient demographic in- formation, diagnoses, treatment records, cost analysis, and regional epidemiological data. It is also important to recognize that using diversion rates as a primary outcome measurement is not without flaw, as its relationship to treatment outcomes and principal cost efficacy have yet to be established.

As with any systems-based model that is reliant on a realworld data, the potential for bias certainly exists and must be acknowledged for the importance of study validity and generalizability to other healthcare institutions and sectors. According to the SAMHSA, West Virginia had the most cases of severe mental illness per capita among adults in the United States, which implies that more patients may be involuntarily committed for mental health treatment than any other state and that the results and data analyzed in this study may not be representative of other state mental hospitals. It is also important to recognize that civil commitment laws may vary in terms of quality and implementation on a state-to-state basis. Regardless, nationally and internationally, addressing capacity issues of psychiatric inpatient services has remained one of the highest priorities for hospital administration and healthcare professionals alike. With these factors in mind, this study was designed to provide a data input model and simulation framework to guide capacity decisions at state psychiatric hospitals, with the final goals of minimizing costs, reducing stress on the current system, and achieving superior outcomes in patient care. In the future, it could be easily expanded and adapted for application in other healthcare settings to address similar challenges.

Meeting the ever-evolving demands of healthcare with a multidisciplinary approach, expanding on study models, and addressing limitations are each essential for successful adaptation, advancement, and optimization of our current system. Future work can focus on expanding our current model to incorporate more input variables, to implement a comparison mechanism aiming to assess and optimize both cost and treatment outcomes. To address quality of care issues, it would be logical to compare the lengths of hospitalization between the diverted and non-diverted patient populations.

\section{Conclusions}

Using a scientific multidisciplinary approach, assimilating the modalities of historical hospital data, statistical analysis, and computer simulation, we were able to successfully build an accurate simulation model capable of predicting system performance in response to multiple scenarios. In analyzing the hospital data, we found that involuntary admissions were unevenly distributed according to geography and population. A computer simulation was developed to reconstruct the admission scenario multiple times. It revealed that a statistically 
significant reduction in diversion rate could be accomplished by altering the variables of hospital capacity, patient arrivals from top referring counties, and patient length of stay. This study represents the approach and framework that can be explored to improve the hospital admission process. Further application and integration will eventually enable hospitals to cost-effectively plan and adapt to both the current and future demands of evolving patient populations.

\section{REFERENCES}

[1] NIMH: Mental Healthcare Cost Data for All Americans. National Institute of Mental Health. 2006 [cited 2015 Jul 6]. Available from: http://www.nimh.nih.gov/health/statistics/cost/me ntal-healthcare-cost-data-for-all-americans-2006. shtml

[2] Mechanic D, McAlpine DD, Olfson M. Changing patterns of psychiatric inpatient care in the United States, 1988-1994. Archives of General Psychiatry. 1998; 55: 785-791. PMid: 9736004. http: //dx.doi.org/10.1001/archpsyc.55.9.785

[3] Stensland M, Watson PR, Grazier KL. An Examination of Costs, Charges, and Payments for Inpatient Psychiatric Treatment in Community Hospitals. Psychiatric Services. 2012; 63(7): 666-71. PMid: 22588167. http://dx.doi.org/10.1176/appi.ps. 201 100402

[4] CDC: Health, United States, 2010 With Special Feature on Death and Dying [Internet]. U.S. Department of Health and Human Services, Centers for Disease Control and Prevention, National Center for Health Statistics, February 2011. DHHS Pub. No. 2011-1232 [cited 2015 Jul 6]. Available from: http://www.cdc.gov/nchs/data/ hus/hus10.pdf

[5] NRI: FY 2009 State Mental Health Revenue and Expenditure Study Results Information from the National Association of State Mental Health Program Directors Research Institute, Inc (NRI) [Internet]. September 2011 [cited 2015 Jul 6]. Available from: http://media.wix.com/ugd/186708_ba1e9f6d213f4 7cdb7b34c261365407d.pdf

[6] Behavioral Health United States 2012 (SAMHSA) [Internet]. U.S. Department of Health and Human Services, Substance Abuse and Mental Health Services Administration [cited 2015 Jul 6]. Available from: http://media.samhsa.gov/data/2012Behavior alHealthUS/2012-BHUS.pdf

[7] Torrey FE, Entsminger K, Geller J, et al. The shortage of public hospital beds for mentally ill persons. A Report of the Treatment Advocacy Center [Internet]. Arlington VA: Treatment Advocacy Center; 2008 [cited 2015 Jul 6]. Available from: http://www.treatmentadvocacycenter.org/storage/do cuments/the_shortage_of_publichospital_beds.pdf

[8] Collis J. Adverse effects of overcrowding on patient experience and care. Emergency Nurse: The Journal of the RCN Accident and Emergency Nursing Association. 2010; 18(8): 34-9. PMid: 21268486. http://dx.doi.org/10.7748/en2010.12.18.8.34.c8152

[9] Virtanen M, Batty GD, Pentti J, et al. Patient overcrowding in hospital wards as a predictor of diagnosis-specific mental disorders among staff: a 2-year prospective cohort study. The Journal Of Clinical Psychiatry. 2010; 71(10): 1308-12. PMid: 20492841. http://dx.doi.org/10.4088/JCP.09m05238blu

[10] Virtanen M, Vahtera J, Batty GD, et al. Overcrowding in psychiatric wards and physical assaults on staff: Data-linked longitudinal study. British Journal of Psychiatry. 2011; 198(2): 149-155. PMid: 21282786. http://dx.doi.org/10.1192/bjp.bp.110. 082388

[11] Manderscheid RW, Atay JE, Crider RA. Changing trends in state psychiatric hospital use from 2002 to 2005. Psychiatric Services.
2009; 60(1): 29-34. PMid: 19114567. http://dx.doi.org/10. $1176 /$ ps. 2009.60.1.29

[12] Fisher WH, Geller JL, Pandiani JA. The changing role of the state psychiatric hospital. Health Affairs. 2009; 28(3): 676-84. PMid: 19414875. http://dx.doi.org/10.1377/hlthaff .28.3.676

[13] Banks J, Carson II JS, Nelson BL, et al. Discrete-Event System Simulation. Prentice Hall. 2001; 3-4. PMid: 21340753.

[14] Lewis PWA, McKenzie E. Simulation Methodology for Statisticians, Operations Analysts, and Engineers. CRC Press; 1988. 9 p.

[15] Sokolowski JA, Banks CM. Principles of Modeling and Simulation. Hoboken, NJ: Wiley; 2009. 6 p. http://dx.doi.org/10.1002/9 780470403563

[16] Colby K. Experimental Treatment of Neurotic Computer Programs. Arch Gen Psychiat. 1964; 10: 220-227. PMid: 14089351. http: //dx.doi.org/10.1001/archpsyc.1964.01720210002002

[17] Feigenbaum EA. The simulation of verbal learning behavior. Proceeding IRE-AIEE-ACM '61 (Western). Western Joint IRE-AIEE-ACM Computer Conference. 1961; 121-132. http://dx.doi.org/10 . 1145/1460690.1460704

[18] Gullahorn JT, Gullahorn JE. A computer model of elementary social behavior. Behavioral Science 1963; 8(4): 354-362. PMid: 5888737. http://dx.doi.org/10.1002/bs. 3830080410

[19] Newell A, Simon HA. The Simulation of Human Thought. The RAND Corp. 1959; 1734.

[20] Jachna JS, Powsner SM, McIntyre PJ, et al. Psychiatry consult adventure simulation. Proceedings - Annual Symposium on Computer Applications in Medical Care. 1989; 1030-1032.

[21] Gorrindo T, Goldfarb E, Birnbaum RJ, et al. Simulation-based ongoing professional practice evaluation in psychiatry: a novel tool for performance assessment. Jt Comm J Qual Patient Saf. 2013; 39(7): 319-23. PMid: 23888642.

[22] Wijk L, Edelbring S, Svensson AK, et al. A pilot for a computerbased simulation system for risk estimation and treatment of mentally disordered offenders. Informatics for Health \& Social Care. 2009; 34(2): 106-15. PMid: 19462270. http://dx.doi.org/10.1080 /17538150903014395

[23] McLay RN, Graap K, Spira J, et al. Development and testing of virtual reality exposure therapy for post-traumatic stress disorder in active duty service members who served in Iraq and Afghanistan. Military Medicine. 2012; 177(6): 635-42. PMid: 22730837. http: //dx.doi.org/10.7205/MILMED-D-11-00221

[24] Amonn F, Frölich J, Breuer D, et al. Evaluation of a computer-based neuropsychological training in children with attention-deficit hyperactivity disorder (ADHD). NeuroRehabilitation. 2013; 32(3): 555-62. PMid: 23648609

[25] Cosić K, Popović S, Horvat M, et al. Computer-aided psychotherapy based on multimodal elicitation, estimation and regulation of emotion. Psychiatr Danub. 2013; 25(3): 340-6. PMid: 24048409.

[26] Gorrindo T, Baer L, Sanders KM, et al. Web-Based Simulation in Psychiatry Residency Training: A Pilot Study. Academic Psychiatry. 2011; 35(4): 232-237. PMid: 21804041. http://dx.doi .org/10 1176/appi.ap.35.4.232 
[27] Treatment Advocacy Center: Research from Treatment Advocacy Center [Internet]. Mental Health Commitment Laws A Survey of the States. February 2014 [cited 2015 Sept 25]. Available from: http://www.tacreports.org/storage/documen ts/2014-state-survey-abridged.pdf

[28] France CA, Mogge NL. Admissions to the State Hospital: a One Year Study. West Virginia Medical Journal. 2010; 106: 23-29. PMid: 21744727.

[29] Schruben LW, Singham DI. Simulating multivariate time series using flocking. Proceeding of the 2010 Winter Simulation Conference. 2010. 1048-1054. http://dx.doi.org/10.1109/WSC. 2010.56 79085

[30] Schruben LW, Singham DI. Data-driven simulation of complex multidimensional time series. ACM Transactions on Modeling and Com- puter Simulation (TOMACS). 2014; 24(1): 5. http://dx.doi.o $\mathrm{rg} / 10.1145 / 2553082$

[31] Efron B, Tibshirani RJ. An introduction to the bootstrap. CRC press; 1994.

[32] United States Census Bureau: American FactFinder [Internet]. Annual Estimates of the Resident Population: April 1, 2010 to July 1, 2013. US Department of Commerce [cited 2015 Jul 6]. Available from: http://factfinder2. census.gov/bkmk/table/1. 0/en/PEP/2013/PEPANNRES/0400000US54.05000

[33] Sood L, Owen A. A 10-year service evaluation of an assertive community treatment team: trends in hospital bed use. Journal of Mental Health. 2014; 23(6): 323-327. PMid: 25222169. http: //dx.doi.org/10.3109/09638237.2014.954694 